\title{
KORELASI ANTARA VARIASI PEMADATANTERHADAP NILAI STABILITAS MARSHALL PADA LASBUTAG CAMPURAN PANAS
}

\author{
Alik Ansyori Alamsyah \\ Jurusan Teknik Sipil - Fakultas Teknik \\ Universitas Muhammadiyah Malang \\ Alamat Korespondensi : Jl. Raya Tlogomas, No.246 Malang \\ Email: alik.syah@yahoo.com
}

\begin{abstract}
Asbuton is one type of natural asphalt from Buton island. How to use existing asbuton diverse as Lasbutag (Buton Asphalt Layers Beragregat) cold mix or ACAS (Aggregate Cold Abuton Sheet), or hot mix Asbuton Ahaz (Aggregate Asbuton Hot Sheet), a hot mixture of non-aggregate Asbuton Nahas (Non Aggregate Asbuton Hot Sheet ) and non-aggregate mixture to cool Asbuton NACAS (Non aggregate cold Asbuton Sheet).

LASBUTAG marshall stability value in the hot mixture showed no variation of the initial value before the collision modifier of $244.772 \mathrm{~kg}$ at $3.6 \%$ : 50\%, while the modifier $3.6 \%$ : $216.73375 \%$ in value, where the stability is eligible for the low traffic . To be used for medium and heavy traffic, the collision is carried out at 49.5 and 224.6. In the hot mixture LASBUTAG modifier composition 3.6\%: 75\%, the collision is carried out for 105 and traffic is heavy at 395. VIM on both compositions are still relatively large and showed a decrease with increasing stability in LASBUTAG hot mixture. VMA qualified on both the composition of the modifier, above 16\%. Flow on LASBUTAG hot mixture showed a trend to decline with the collision. From the test results and analysis show that the compaction of different variations affect the stability of the marshal.
\end{abstract}

Keywords: Lasbutag, Variations Compaction, Mixed Heat

\section{PENDAHULUAN}

Indonesia merupakan Negara dengan beribu pulau yang memiliki keanekaragaman material dan sumber daya, sehinggga memungkinkan memiliki banyak jenis perkerasan yang semuanya memiliki keuntungan dan kerugiannya. salah satu jenis perkerasan yang mempunyai mutu paling baik adalah aspal beton. Problem kontruksi jalan raya di indonesia yang sering dihadapai adalah kerusakan jalan, antara lain retak, gelombang, alur, lendutan dan bleeding akibat beban lalu lintas berat dan lingkungan suhu tinggi ( Heri Rudianto, 2000 )

Menurut Alik Ansyori (2009), asbuton merupakan salah satu jenis aspal alam yang berasal dari pulau Buton. Cara penggunaan asbuton ada bermacam-macam seperti Lasbutag (Lapisan Aspal Buton Beragregat) campuran dingin, yaitu campuran dari bahan Asbuton, modifier dan tambahan agregat yang dapat digunakan sebagai bahan perkerasan jalan dimana cara percampuranya seluruhnya tanpa dipanasi, Lasbutag ini juga dikenal dengan istilah ACAS (Agregat Cold Abuton Sheet) serta Asbuton campuran panas yang disebut dengan AHAS (Agregat Hot Asbuton Sheet) ada juga Asbuton campuran panas non agregat NAHAS (Non Agregat Hot Asbuton Sheet) serta Asbuton campuran dingin non agregat NACAS (Non Agregat Cold Asbuton Sheet). Pada prinsipnya bahan bitumen pada Asbuton dapat digunakan sebagai bahan perkerasan dan bahan mineral Asbuton yang sebagian besar berupa batu kapur juga dapat digunakan sebagai bahan agregat perkerasan jalan raya. Hanya umumnya perlu tambahan agregat kasar yang lain untuk mendukung kompsisi campuran

Pemadatan sebagaimana diketahui akan mempengaruhi stabilitas, kekuatan, keawetan dan tendensi terjadinya alur - alur roda akibat lalu lintas. Permukaan Aspal beton yang dipadatkan dengan baik tahan terhadap perembesan air dan tetap memiliki koefisien friksi yang tinggi. 
Sehingga pemadatan dengan objek studi penggunaan Asbuton berkembang pesat dengan tujuan mengatasi problem kontruksi jalan raya akibat beban lalu lintas tinggi. Salah satunya dengan melakukan pengujian terhadap campuran aspal pada LASBUTAG dengan variasi Demadatan.
Tujuan dari penelitian ini adalah untuk mengetahui korelasi antara variasi pemadatan terhadap nilai stabilitas marshall pada lasbutag campuran panas.

\section{METODOLOGI PENELITIAN}

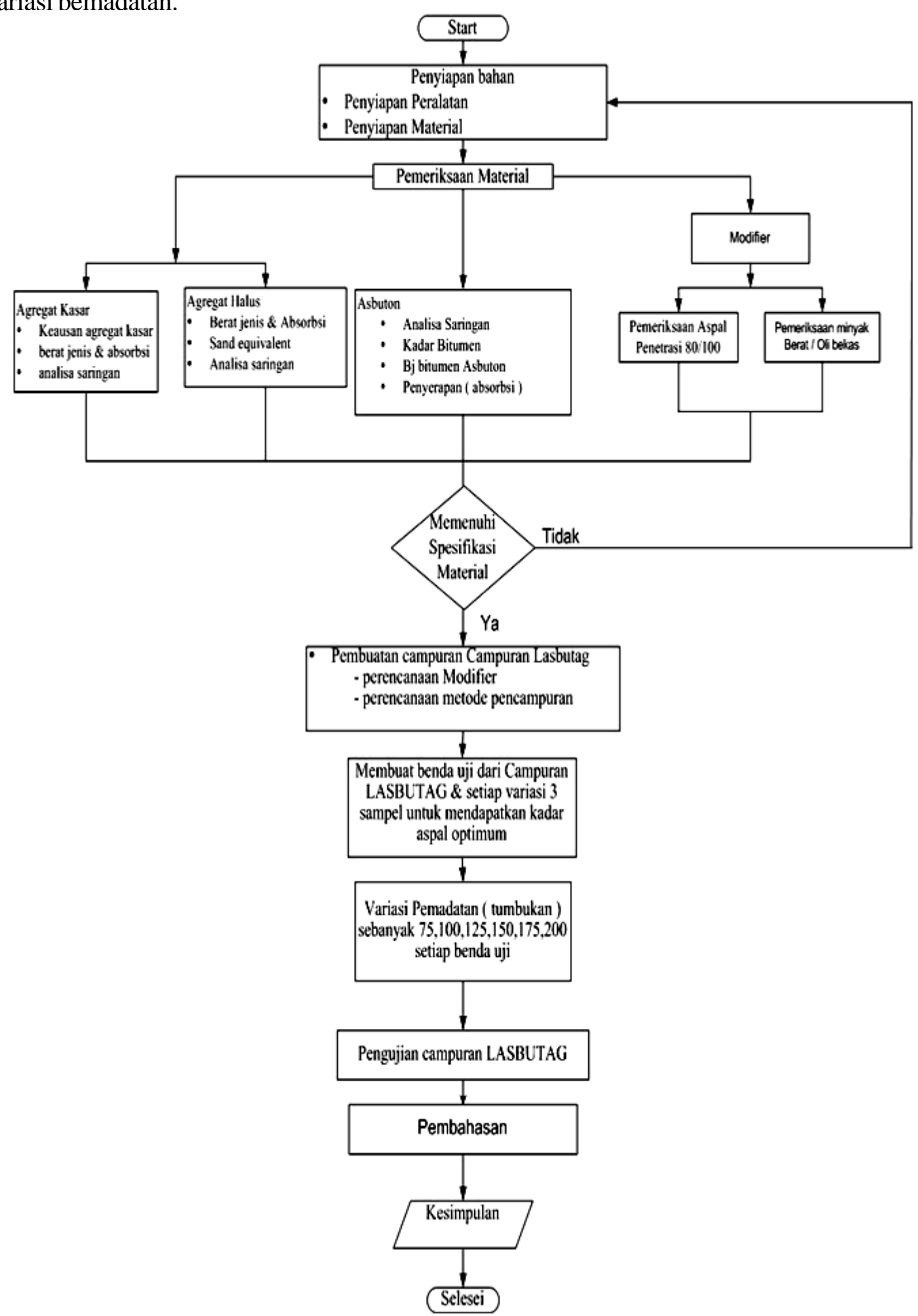

Umum

Gambar 1. Diagram Alur Penelitian

Penelitian LASBUTAG Campuran Panas dilaksanakan pada awal pertengahan Oktober 2011 sampai Juni 2012. Sedangkan pelaksanaan penelitian dari pemeriksaan material sampai pengujian benda 
dilaksanakan di Laboratorium Teknik Sipil Universitas Muhammadiyah Malang. Penelitian material LASBUTAG campuran Panas yang meliputi:

- $\quad$ Asbuton

- Agregat

- $\quad$ Aspal minyak

- Minyak berat

a. Jumlah tumbukan pada waktu pemadatan benda uji yaitu 50, 75, 100,125, 150,175, dan 200

b. Kondisi test dilakukan dalam kondisi Hotbaht, yaitu direndam air murni dengan suhu $60^{\circ}$ selama 30 menit

c. Pelaksanaan test marshall dilakukan untuk mencari harga - harga stabilitas, flow, marshall Question, density, rongga dalam campuran, rongga antar agregat dan rongga terisi bitumen

\section{Perencanaan modifier}

Bahan utama yang digunakan dalam penelitian ini adalah campuran antara minyak berat (oli bekas) + Asmin. Modifier yang digunakan dalam penelitian ini ditentukan dengan komposisi campuran sebagai berikut

a. Data pada penelitian pendahuluan digunakan sebagai acuan setelah ditentukan nilai terbaik penggunaan asmin. Hasil dari variasi Asmin terbaik adalah $3.6 \%$ dengan Oli bekas direncanakan $50 \%$ dari jumlah asbuton. Tumbukan dilakukan sebanyak 75 x 2 serta perendaman terhadap benda uji dilakukan selama 24 jam.

b. Pada penelitian ini modifier pada komposisi campuran I (satu) di rencanakan dengan perbandingan sebanyak 3.6\% Asmin dan 50\% Oli bekas

c. Modifier Pada komposisi Campuran II (dua) direncanakan dengan perbandingan 3.6\% Asmin dan $75 \%$ oli bekas.

\section{Perencanaan Metode Pencampuran} berikut:

Di gunakan metode pencampuran sebagai

a. Digunakan asmin yang sudah di encerkan seluruhnya dengan minyak berat ( oli bekas ) .dipanaskan pada suhu $90^{\circ} \mathrm{C}$. b. Aggregat dan bahan asbuton yang sudah dicampurkan dipanaskan pada suhu $110^{\circ} \mathrm{C}$.

c. Agregat yang telah dipanaskan pada suhu $110^{\circ}$ C dapat dicampurkan kedalam adukan terakhir ini dengan suhu $140^{\circ} \mathrm{C}$, susunan gradasi agregat dan jumlahnya sudah ditentukan sebelumnya.

d. LASBUTAG campuran panas sebelum dipadatkan dapat diperam terlebih dahulu atau tidak diperam (langsung dipadatkan) tergantung dari total kadar bitumen dalam campuran, pemeraman sebelum pemadatan lebih baik disarankan untuk campuran dengan kadar bitumen relatife rendah (sekitar 5\% - 6,5\%)

\section{HASIL DAN PEMBAHASAN}

\section{TEST dan ANALISAASBUTON}

Pemeriksaan asbuton meliputi :

Kadar Bitumen Asbuton ( AASHTO T - 164 )

Tabel 1. Test Kadar Bitumen Asbuton

\begin{tabular}{|c|c|c|}
\hline \multirow{2}{*}{ Pemeriksaan } & \multicolumn{2}{|c|}{ Uji Benda } \\
\hline & $\mathrm{I}$ & II \\
\hline Berat kertas Filter (A) & 5.70 & 5.80 \\
\hline Berat Benda uji + kertas & 505.70 & 505.80 \\
\hline $\begin{array}{lll}\begin{array}{l}\text { Filter } \\
\text { ekstraksi }\end{array} & \text { sebelum } & \text { di }\end{array}$ & & \\
\hline $\begin{array}{l}\text { Berat benda uji sebelum } \\
\text { di ekstraksi ( } \mathrm{C}=\mathrm{B}-\mathrm{A} \text { ) }\end{array}$ & 500.00 & 500.00 \\
\hline $\begin{array}{l}\text { Berat benda uji }+ \text { kertas } \\
\text { filter setelah di ekstraksi } \\
\text { (D ) }\end{array}$ & 394.40 & 404.20 \\
\hline $\begin{array}{l}\text { Berat benda uji setelah di } \\
\text { ekstraksi }(E=D-A)\end{array}$ & 388.70 & 398.40 \\
\hline $\begin{array}{l}\text { Kadar } \\
\{[\mathrm{C}-\mathrm{E}] / \mathrm{C}] \mathrm{x} 100 \%\end{array}$ & 22.26 & 20.32 \\
\hline $\begin{array}{l}\text { Kadar aspal rata - rata ( } \\
\% \text { ) }\end{array}$ & 21.29 & \\
\hline
\end{tabular}


Asbuton yang dipakai dalam penelitian ini adalah Asbuton B - 20, Karena Mempunyai kadar Bitumen $18.0 \%-22,5 \%$

\section{Berat Jenis Asbuton}

Tabel 2. Berat jenis Asbuton

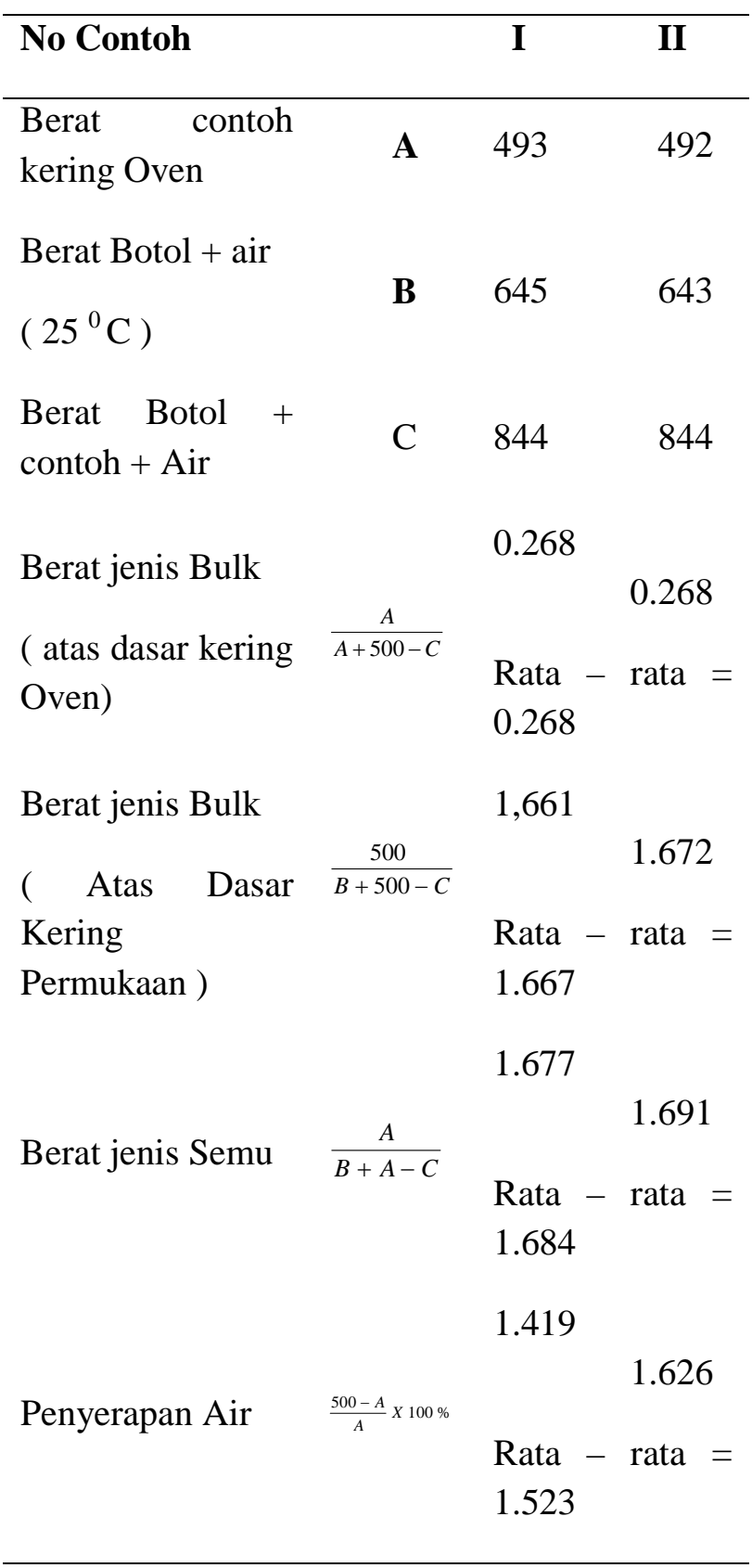

Sumber: (Hasil pemeriksaan bahan )
TESTDANANALISAASPALMINYAK

Tabel 3. Hasil Pemeriksaan Test Aspal Pen 80/100

\begin{tabular}{|c|c|c|c|c|}
\hline NO & $\begin{array}{c}\text { JENIS } \\
\text { PEMERI } \\
\text { KSAAN }\end{array}$ & $\begin{array}{c}\text { CARA } \\
\text { PEMERI } \\
\text { KSAAN }\end{array}$ & HASIL & $\begin{array}{l}\text { SATU } \\
\text { AN }\end{array}$ \\
\hline 1 & Penetrasi & $\begin{array}{c}\text { PA } \\
0301-76\end{array}$ & 96 & $\begin{array}{r}0,1 \\
\mathrm{~mm}\end{array}$ \\
\hline 2 & $\begin{array}{l}\text { Titik } \\
\text { Lembek }\end{array}$ & $\begin{array}{c}\mathrm{PA}- \\
0302-76\end{array}$ & 47 & ${ }^{0} \mathrm{C}$ \\
\hline 3 & Titik Nyala & $\begin{array}{c}\mathrm{PA}- \\
0303-76\end{array}$ & 318 & ${ }^{0} \mathrm{C}$ \\
\hline 4 & Daktilitas & $\begin{array}{c}\mathrm{PA}- \\
0306-76\end{array}$ & 102,67 & $\mathrm{Cm}$ \\
\hline
\end{tabular}

Sumber: (Hasil pemeriksaan bahan )

Aspal Pen 80/100 Dapat dipergunakan, karena sesuai dengan persyaratan yaitu daktilititas minimum $100 \mathrm{~cm}$.

\section{Pengaruh Pemadatan Terhadap Nilai Stabilitas} Marshall

\section{Analisa Regresi Stabilitas}

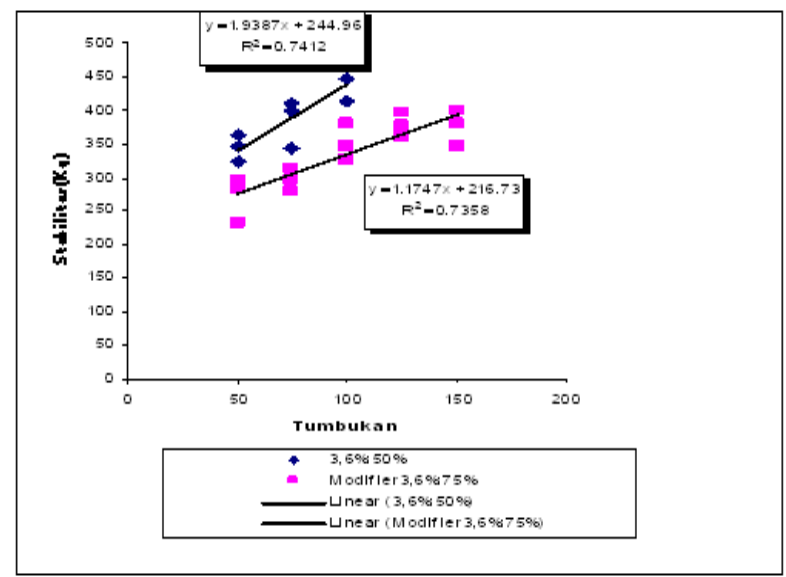

\section{Gambar 2. Grafik Hubungan Antara Pemadatan Dengan Nilai Stabilitas (kg)}

Dari uji statistik didapat bahwa ada pengaruh akibat variasi pemadatan terhadap stabilitas pada campuran LASBUTAG varian 3,6\%:50\%, hal ini 
ditandai dengan adanya yang dikenaikan dinyatakan dengan persamaan regresi $\mathrm{Y}=1,9387 \mathrm{X}+244,96$. Pada perencanaan modifier 3,6\% : 75\% persamaannya adalah $\mathrm{Y}=1,1747 \mathrm{X}+216,73$. Kenaikan akibat tumbukan dinyatakan dengan angka positif $(+)$ pada koefisien 1,1747, yang menyatakan bahwa setiap penambahan 1 (satu) tumbukan akan meningkatkan nilai stabilitas sebesar 1,1747, sedangkan konstanta 216,73 menyatakan bahwa jika tidak ada tumbukan, maka nilai stabilitas adalah 216,73.

Variasi tumbukan berpengaruh terhadap nilai stabilitas, terlihat dari nilai $\mathrm{F}_{\text {hitung }}>\mathrm{F}_{\text {tabel. }}$ Prosentase stabilitas sebesar 74\% dapat dijelaskan oleh variasi pemadatan. Sedangkan sisanya 26\% dapat dijelaskan oleh sebab - sebab yang lain.

Dari hasil penelitian LASBUTAG campuran panas pada gambar 2. komposisi modifier $3.6 \%$ : 50

\% persamaan stabilitasnya adalah $\mathrm{Y}=1,9407 \mathrm{X}+$ 244,96 . Besar tumbukan yang dibutuhkan agar dapat dipergunakan untuk lapisan perkerasan lalu lintas berat adalah 224,53 atau 225 tumbukan

Persamaan stabilitas pada perencanaan 3,6\%: $75 \%$ adalah $Y=216,733+1,1746$ X. Sedangkan besar tumbukan yang dibutuhkan agar dapat dipergunakan untuk lapisan perkerasan lalu lintas berat adalah 395 tumbukan.

Pemadatan pada kedua komposisi perencanaan modifier, nilai stabilitasnya masih dapat digolongkan untuk lalu lintas rendah dan sedang.

\section{Pengaruh Variasi Pemadatan Terhadap Nilai VIM}

\section{Analisa Regresi VIM}

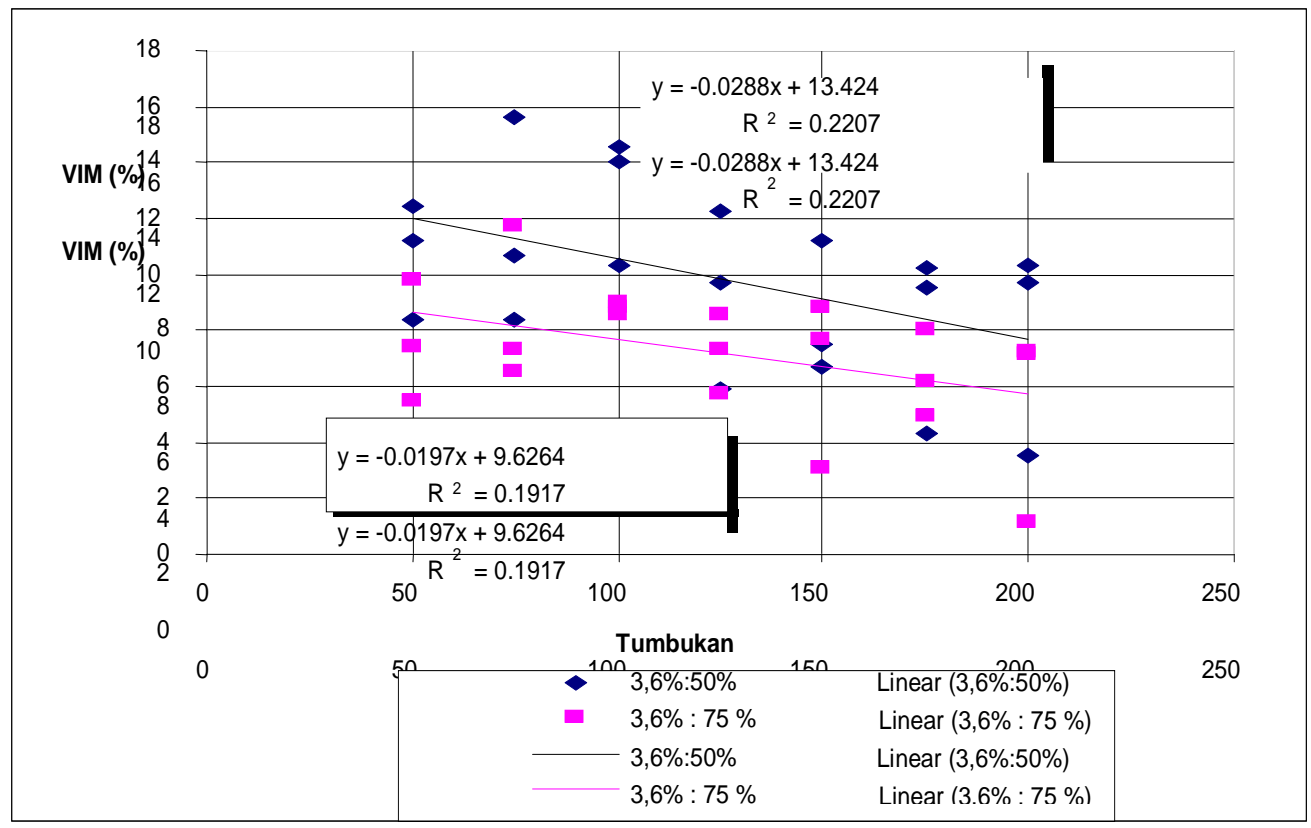

\section{Gambar 3. Grafik Hubungan Antara Pemadatan Dengan Void In Mineral}

Dari gambar 3 didapat persamaan regresi $\mathrm{Y}_{3,6 \%: 50 \%}=13,424-0,0287 \mathrm{X}$. Hal ini menjelaskan bahwa nilai awal void in mineral (VIM) sebesar 13,424 . Sedangkan angka koefisien menunjukan besarnya penurunan akibat tumbukan pada LASBUTAG campuran panas.

Nilai R square menyatakan bahwa 22\% rongga udara dapat dijelaskan oleh adanya tumbukan, sisanya diterangkan oleh sebab - sebab yang lain.

Kedua komposisi mempunyai pengaruh yang berbeda terhadap air void, dimana masing - masing dijelaskan dengan besarnya angka koefisien determinasi dan besar koeffisien pada persamaan rongga udara. Angka koeffisien determinasi untuk perencanaan modifier 3,6\%: 50\% adalah sebesar 0,2207, sedangkan koeffisien pada persamaannya adalah 0,0288 . Sedangkan pada komposisi perencanaan modifier 3,6\% : 75\%, angka R square adalah 0,19.

Angka pada tabel 6 dan 7. menunjukan adanya pengaruh pemadatan terhadap rongga udara pada kedua perencanaan modifier, dimana $\mathrm{F}_{\text {hitung }}>\mathrm{F}_{\text {tabel. }}$ memperlihatkan adanya pengaruh. 
Pengaruh Variasi Pemadatan Terhadap Nilai VMA

\section{Analisa Regresi VMA}

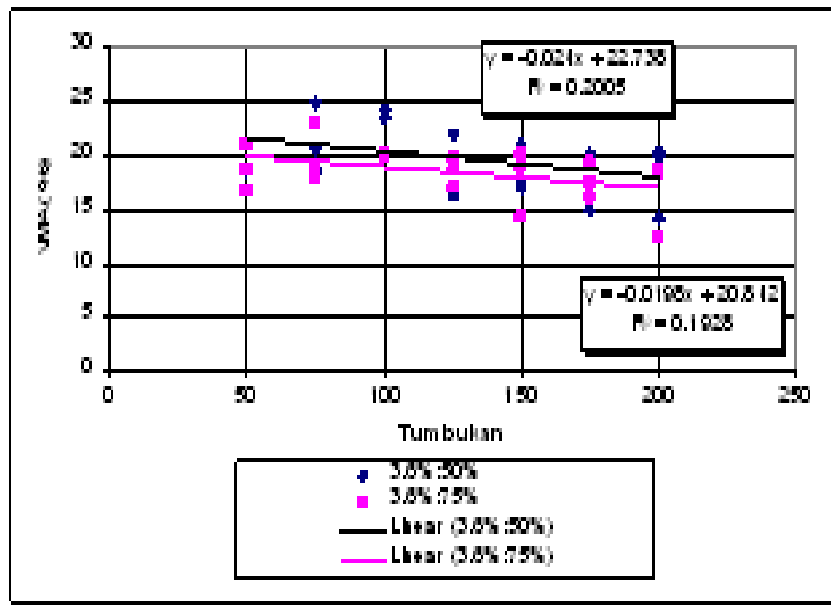

\section{Gambar 4. Grafik Hubungan Antara Pemadatan Dengan VMA}

Dari uji statistik pada LASBUTAG campuran panas didapatkan persamaan $\mathrm{Y}_{3,6 \%: 50}=22,738-0,024$ $X$ dan $Y_{3,6 \%: 75}=20,842-0,0197 X$. Persamaan tersebut menyatakan besarnya penurunan dan nilai awal rongga udara antar agregat.

Prosentase pengaruh adanya hubungan dinyatakan dengan angka $\mathrm{R}$ square sebesar 0.20 atau $20 \%$ yang artinya prosentase kadar rongga antar agregat (VMA) dapat dijelaskan oleh variasi pemadatan. Sedangkan sisanya ( $100 \%-20 \%=80 \%$ ) dijelaskan oleh sebab - sebab yang lain. Nilai R square berkisar antara pada angka 0 sampai 1 , dengan catatan semakin kecil angka $\mathrm{R}$ square, semakin lemah hubungan kedua variabel.

Gambar 4 memperlihatkan adanya penurunan akibat penambahan tumbukan pada kedua campuran. Terjadinya penurunan pada campuran LASBUTAG campuran panas disebabkan karena agregat yang tadinya sudah padat pada tumbukan ke $50 \times 2$ bertambah padat dengan adanya butiran akibat tumbukan berikutnya yang mengisi rongga.

Nilai kadar rongga antar agregat dalam campuran pada agregat lolos saringan 3/8 minimum adalah $16 \%$, sedangkan nilai VMA pada LASBUTAG campuran panas berada diatas $16 \%$. sehingga LASBUTAG campuran panas pada perencanaan modifier prosentase minyak berat yang berbeda memenuhi syarat.

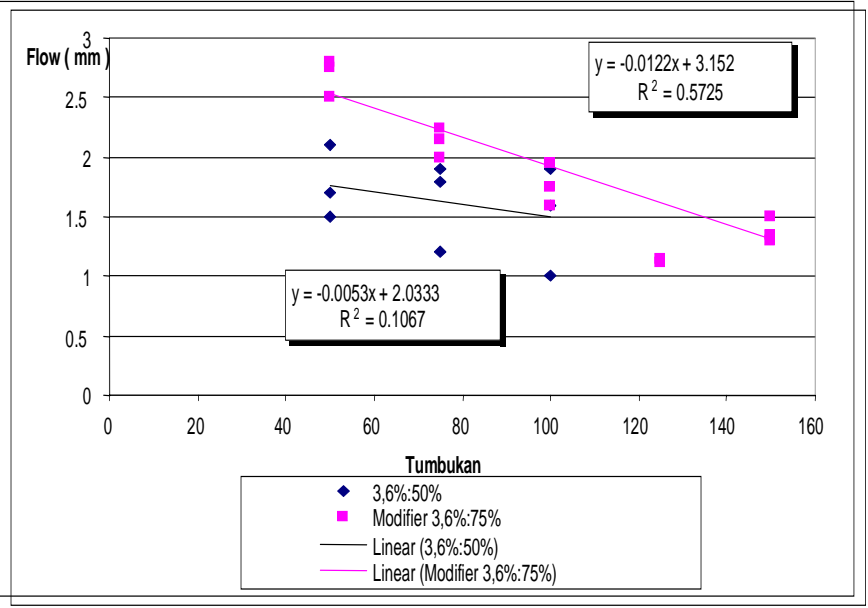

\section{Gambar 5. Grafik Hubungan Antara Pemadatan Dengan Flow (mm)}

Dari uji statistik didapat Nilai persamaan $\mathrm{Y}_{3,6 \%: 50 \%}$ $=2,0333-0,0053 X$ dan $Y_{3,6 \%: 75 \%}=3,152-0,0122 X$, dimana $\mathrm{Y}$ adalah flow dan $\mathrm{X}$ adalah variabel bebas. Angka konstanta pada persamaan menunjukan besarnya flow sebelum dilakukan tumbukan. Koeffisien pada kedua persamaan menyatakan besar penurunan yang terjadi pada satu kali tumbukan. Nilai R Square merupakan pengkuadratan dari r koefisien korelasi., dimana dari dari grafik nilai R square sebesar 0,24 (Pembulatan) artinya 24\% flow dapat dijelaskan oleh variabel tumbukan.

Besarya penurunan Flow pada LASBUTAG campuran panas pada uji adalah sebesar 0,0053 pada perencanaan $50 \%$ oli bekas. Sedangkan pada perencanaan $75 \%$ oli bekas, angka penurunannya sebesar 0,0122. Angka R square jauh dari 1, menyatakan lemahnya pengaruh antara tumbukan dan kelelehan.

Penurunan flow disebabkan karena agregat yang sudah padat mengalami retak dan pecah sehingga aspal yang seharusnya melekat pada agregat (kohesi)tidak mengikat bagian yang terpecah saat dilakukan pengujian

\section{KESIMPULAN DAN SARAN}

Dari hasil analisa dan pembahasan LASBUTAG campuran panas terdapat pengaruh variasi pemadatan terhadap parameter marshall sebagai berikut:

-- Stabilitas 
Nilai stabilitas marshall pada LASBUTAG campuran panas menunjukan nilai awal sebelum ada variasi tumbukan sebesar $244,772 \mathrm{~kg}$ pada modifier 3,6\%:50\%, sedangkan pada modifier 3,6\%: 75\% nilainya 216,733, dimana nilai stabilitas tersebut memenuhi syarat untuk lalu lintas rendah. Besarnya pengaruh variasi pemadatan juga diperlihatkan dengan angka koefisien dalam persamaan regresi dan agar dapat dipergunakan untuk lalu lintas sedang dan berat, tumbukan yang dilakukan sebesar 49,5 dan 224,6.

Pada LASBUTAG campuran panas komposisi modifier 3,6\%: 75\%, tumbukan yang dilakukan sebesar 105 dan untuk lalu lintas berat sebesar 395 tumbukan.

-- $\quad$ Nilai Void In Mix (VIM)

Nilai void in mix pada kedua komposisi menunjukan penurunan seiring dengan bertambahnya stabilitas pada LASBUTAG campuran panas. Namun, nilai VIM pada kedua komposisi masih relatife besar di atas persyaratan minimal-maksimal.

-- $\quad$ Void In Mineral Agregat (VMA)

Garis regresi pada gambar 4. LASBUTAG campuran panas menunjukan trend adanya penurunan, hal ini disebabkan adanya desakkan antar agregat yang menimbulkan friksi. Nilai Void In Mineral (VMA) memenuhi syarat pada kedua komposisi modifier, di atas $16 \%$.

- $\quad$ Nilai Flow

Flow pada LASBUTAG campuran panas menunjukan trend menurun seiring dengan pertambahan tumbukan. Penurunan pada flow dikarenakan rendahnya kadar bitumen pada campuran yang mengikat agregat. Pada penelitian didapatkan besarnya penurunan pada persamaan matematis regresi linear dan didapatkan nilai, bahwa pada tumbukan ke 50 dan 75 flow masih memenuhi pesyaratan minimum-maksimum komposisi 3,6\%:50\%.

\section{DAFTAR PUSTAKA}

Ansyori, Alik, 2009, Penggunaan Pertamax Sebagai Modifier pada Lasbutag Untuk Perkerasan Jalan, Laporan Penelitian, DP2P UMM, Malang.
Bina Marga, 1991, Manual Pemeriksaan Bahan Jalan , No. 01/ MN/ 1991, Departemen Pekerjaan Umum.

Bina Marga, 1998, Petunjuk Pelaksanaan Lapisan Asbuton Aggregat LASBUTAG ), Report No. 09/ PT/ B/ 1998

James, EM, 1997, Asbuton Modifier Selection, Designing and Spesification on Lasbutag Mixes, Part I, Report No. 3, Asbuton Spesification Development Project, Direktorat Jenderal Bina Marga.

Tjitjik, S. \& Sastramihardja, R., 1998, Karakteristik Bitumen Asbuton, Proceeding dari Konferensi Tahunan Jalan ke - 1, Bandung.

Suroso, TW, 2000, Pelapukan (Ageing) Asmin pada Perkerasan Jalan, Proceeding dari Konferensi Tahunan Teknik Jalan ke 3, Bandung.

Rudianto, Heri, 2000, Penggunaan Modifier Campuran Kerosen dan Premium Pada Lasbutag dengan Sistem Cold Mix, Laporan Penelitian - Jurusan Teknik Sipil ITS, Surabaya. 